Theories \& Applications, the International Edition

Printed Version: (ISSN 2090-5262)

Online Version: (ISSN 2090-5270)

November 2012, Volume 2, No. 3 Pages (1 - 10)

\title{
The Frequency and Relationship Between Injury Incidence and Players' Positions in Female Field Hockey
}

\author{
Aliaa Mohamed Azmi*
}

\begin{abstract}
:
The aim of this study was to examine the frequency and relationship between injury incidence and players' positions in female field hockey. Previous researches proved that goalkeepers would have the highest rate of injury, followed by forwards. 158 female field hockey players at the FIH Champions Challenge II (Women) 2011 completed an anonymous questionnaire. They reported personal characteristics (age, height, weight); field hockey information (level, years of experience, surface); injury history (type, site, cause, severity); and back pain information. Injury rates were calculated per athlete-year. The most frequently injured site of the body was the lower limb (51\%), followed by the head/face (34\%), upper limb (14\%), and torso (1\%). The most prevalent types of injuries were ankle sprains, followed by hand fractures and head/face injuries. Goalkeepers had the highest rate of injury (0.58 injuries/athlete-year), whereas midfielders were the most injured field players (0.36 injuries/athlete-year). Back pain was reported by 59\% of the sample, and the lower back was the most common site of this pain. The researcher concluded that there are differences in the rates of injury among playing positions in female field hockey and in the types of acute injury sustained at each position. The high number of injuries to the head and face region is also cause for concern. Although most of these injuries are minor, the serious injuries that do occur can be very severe. The researcher recommends that further examination of the playing situations that lead to injury should be undertaken to design proper prevention strategies.
\end{abstract}

Keywords: field hockey - injuries - playing position - frequency

\section{Introduction:}

$\mathrm{F}_{\mathrm{e}}$ ield hockey is one of the oldest sports in existence: 4,000 year-old wall decorations from the tomb of Kheti in Egypt depict players with rudimentary "crooks" and a ball. The modern game of field hockey was subsequently developed in England in the mid-19th century and exported to the United States as a women's sport in 1901. Interest in field hockey has grown dramatically in North America, and today there are more than 5,000 women competing at the collegiate level each year. As the sport has evolved, it has become faster-paced and more physical. As a result, the number of and severity of injuries has increased.

It is also one of the most popular team sports in

* Assistant Professor, Department of Games, Faculty of Physical Education for Girls, Zagazig University, Egypt. the world, second only to soccer. In fact, the International Hockey Federation consists of five continental associations and 119 member associations which reflect the extensive participation, which provide a feeder system for higher levels of play. Despite the sport's apparent popularity, the data on injury rates among field hockey players are limited.

The majority of the injuries reported are minor ankle sprains and contusions. More serious injuries, such as torn knee ligaments, concussions, and eye trauma leading to blindness, have also been noted $(1,4,6$, and 21). Because these studies tend to focus on elite level athletes, it has been difficult to generalize their results to the field hockey community as a whole. Some authors suggest that increased skill, conditioning and a smooth playing surface decrease the risk of injury $(6,17,21$, and 23$)$. Others indicate that elite players not only have 
an increased "exposure time," but they may be prepared to take more risks $(1,12)$.

Most of the research on field hockey was completed over $10 \mathrm{yr}$ ago, and yet the game has undergone significant changes since that time. For example, since the 1976 Olympic

Games, more athletes are practicing and playing on artificial turf than ever before. Also, recent advances in stick construction such as shape and new reinforcement materials allow players to manipulate the ball with more power and accuracy. Finally, there have been numerous rule changes. The offside rule has been eliminated, and alterations to the substitution guidelines allow the prompt and frequent interchange of players. Some players and coaches believe that the removal of the offside rule leads to more players around the goal area and an increased risk of injury. These changes were initiated to promote fast-paced, continuous play and have significantly decreased recovery periods for every player except the goalkeeper (2).

The role of position has received little or no attention in previous field hockey injury reports. The NCAA records the position played at the time of injury (18). However, they do not report the number of athletes who play each position or the type of injury sustained. The remaining information is based on anecdotal evidence: "Which positional role is at greatest risk is difficult to establish. However, play is most intense in and near the striking circle. The goalkeeper, although normally wearing protective equipment, is called upon to come into deliberate physical contact with the ball and must therefore play a high-risk role, as do attackers who rush toward him to retrieve rebounds. Such is the nature of the game that all players are vulnerable most of the time and are involved in most of the high risk situations that arise" (6).

It is not uncommon for players to crowd the goal area. A more recent comment by Spedding (23) suggested that the modern game was safer for most players, except for goalkeepers who had started to lie horizontally across the goal when defending penalty corners. Moore (17) also supports the contention that goalkeepers are at the highest risk of injury, because lofted shots and rebounds off sticks are common in the goal area. Another concern of field hockey players is back pain. A questionnaire administered by Reilly and Seaton (20) (81\% response rate) revealed that $53 \%$ of field hockey players have experienced back pain at some time. There has been an increase in recent reports of low back pain of unknown origin in female players (5). Most therapists seem to classify these occurrences as overuse injuries. Field hockey is a game with an inbuilt asymmetry. All sticks are right-handed and approximately $0.91 \mathrm{~m}$ long. The rules require that only one side of the stick be used during play. Therefore, most ball handling and defensive skills demand a combination of trunk flexion and rotation. This semi-crouched position causes greater spinal loading than normal locomotion and is thought to be ergonomically unsound (20). Previous research on back pain in field hockey players has focused on this semi crouched position as the underlying cause of injury and pain.

The aim of this study was to examine the frequency and relationship between injury incidence and players' positions in female field hockey by identifying the injury rates among different positions. Based on the available accounts, it was proven that goalkeepers and forwards would have the highest rate of injury. An understanding of these patterns is crucial for developing conditioning and training programs that could be useful for injury prevention. This information could also be used to address the potential need for rule changes or additional protective equipment.

A cross-sectional design was chosen as the most efficient method for reaching the largest and most diverse sample of female field hockey players. The major limitations of this strategy were that it relied heavily on the athletes' abilities to accurately recall their injuries and it was not possible to calculate the number of injuries per athlete exposure. For example, clinical details may not be reliable and there is a tendency for adverse events to be recalled as more recent than they actually occurred (26). However, the cross-sectional design was suitable for a descriptive study of the prevalence of injury and the relationships between injury and other factors (such as playing position) in a defined population. It was also not as subject to yearly fluctuations as the case series method 
(26). Focusing on acute injuries minimized the effects of recall bias. The exact timing of this injury or the severity of symptoms associated with the injury was not required.

\section{Research procedures:}

The international hockey federation's medical committee was contacted for permission to use the report outcomes for injury screening that took place in FIH Champions Challenge II (Women) 2011 in May 7-15, 2011 in Vienna, AUSTRIA to enroll these screening reports in the study. The committee co-operated positively and sent all required questionnaires where the researcher got the required raw data from.

\section{Sample:}

The final sample consisted of 158 female field hockey players after removing incomplete questionnaires. The mean age of players in the final sample was $19.8 \mathrm{yr}$ (range 14-32 yr) with a mean of 6.8 (6 3.5) yr of playing experience. Among these athletes, there were 30 with only high school experience, 23 intermediate level players (club and/or provincial experience), 75 varsity athletes, and 30 national level players.

Table (1)

Personal characteristics of the female field hockey players in the sample, categorized according to the position played with mean values followed by SD's

\begin{tabular}{|c|c|c|c|c|c|c|}
\hline & Goal $\mathbf{n = 1 1}$ & $\begin{array}{c}\text { Backfield } \\
\mathbf{n = 4 4}\end{array}$ & $\begin{array}{c}\text { Midfield } \\
\mathbf{n = 2 7}\end{array}$ & $\begin{array}{c}\text { Forward } \\
\boldsymbol{n}=\mathbf{4 6}\end{array}$ & $\begin{array}{c}\text { Multiple } \\
\boldsymbol{n}=\mathbf{3 0}\end{array}$ & Total $\mathbf{n = 1 5 8}$ \\
\hline Age & $20.4(3.8)$ & $19.3(2.9)$ & $20.0(3.6)$ & $19.6(3.0)$ & $20.4(3.7)$ & $19.8(3.25)$ \\
\hline Experience & $8.1(4.0)$ & $6.7(3.6)$ & $6.8(2.9)$ & $6.3(2.9)$ & $7.4(4.3)$ & $6.8(3.5)$ \\
\hline Height & $1.68(0.05)$ & $1.64(0.06)$ & $1.65(0.05)$ & $1.63(0.09)$ & $1.64(0.07)$ & $1.64(0.07)$ \\
\hline Mass & $65.3(13.0)$ & $61.7(9.7)$ & $61.1(6.1)$ & $60.3(5.9)$ & $60.8(5.8)$ & $61.3(7.8)$ \\
\hline
\end{tabular}

\section{Research questionnaire:}

The required information was obtained from an anonymous questionnaire that was designed for quick and easy use and took approximately 15 min to complete. It included personal information such as age, height, weight, position, and playing experience. The questionnaire also inquired about injury history and back pain. The athletes reported the anatomic site of injury, number of occurrences, if medical treatment was sought, and the cause of the injury (ball, stick, player contact, or playing surface contact). Respondents were then asked whether the injury affected their performance or caused them to miss field hockey games and/or practices.

Personal information, back pain data, and the acute injuries that had occurred during a field hockey game or practice were included in the subsequent analysis. These restrictions accounted for any acute physical damage, such as contact injuries from playing equipment, another player, or the playing surface and noncontact injuries, such as muscle strains and ligament sprains. Chronic injuries due to prolonged strain, such as stress fractures, shin splints, and compartment syndrome, were not considered in this study.

The data were entered into a Microsoft Access TM database. To determine whether the differences between selected variables were significant, a multiple factor analysis of variance (ANOVA) was used. A P-value of less than 0.05 was selected for rejecting the null hypothesis.

\section{Results:}

Of the 158 athletes surveyed, $49 \%$ reported that they regularly trained and played on artificial turf, $21 \%$ participated on grass, and $30 \%$ indicated that they used both surfaces equally. At least one acute injury that had occurred during a field hockey game or practice was reported by $74.7 \%$ of these athletes. The injured athletes had an average age of $20.4 \mathrm{yr}$ and $7.4 \mathrm{yr}$ of experience. The uninjured athletes were significantly younger and had less experience with an average age of 18.0 (62.6) $\mathrm{yr}$ and 5.4 (63.5) yr of experience $(\mathrm{P}, 0.05)$. 
Figure (1)

Types of acute injuries sustained by female field hockey players during a game or practice
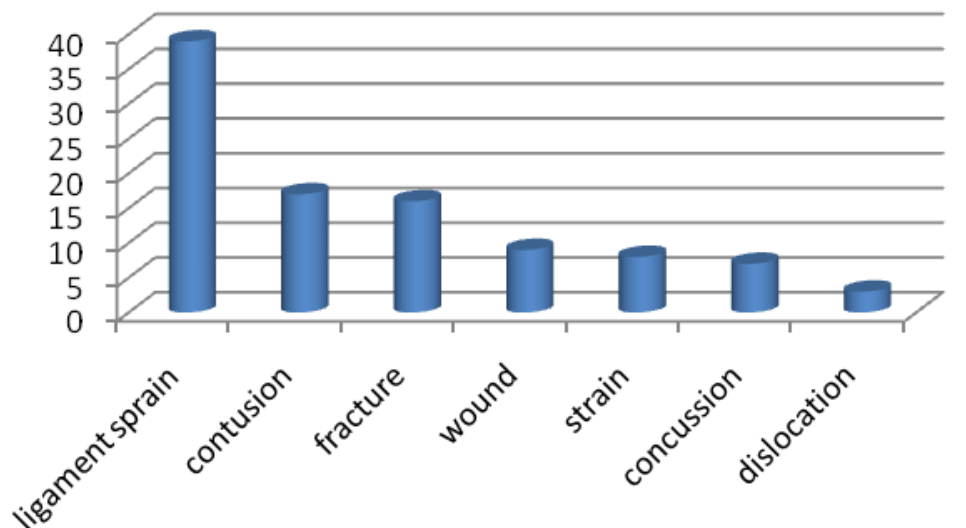

Approximately half of the 469 injuries that occurred were to the lower limb. The next most frequent site of injury was the head/face area, followed by upper limb and torso "back". The most common type of injury was a ligament sprain $(39.7 \%$ of total injuries) and most of these were ankle sprains. Because these sprains were self-reported, the severity could not be assessed. Other prevalent injuries were contusions and fractures $(17.1 \%$ and $16.4 \%$, respectively). Most contusions occurred to the head/face region, whereas most of the fractures involved bones of the wrist or hand. Of the remaining $26.9 \%$ of the injuries, $9.4 \%$ were wounds, $8.1 \%$ were muscle strains, $7.7 \%$ were concussions, and, finally, $1.7 \%$ were dislocations.

Figure (2)

Anatomical site of acute injuries to female field hockey players that occurred during a field hockey game or practice

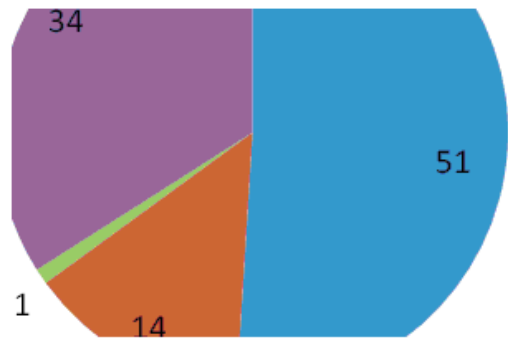

The percentage of athletes who had sustained at least one injury to the head or face region was $34 \%$. These respondents were asked whether the injury was caused by a field hockey ball, stick, player, or contact with the playing surface. The most commonly reported cause was the ball, next was the stick or another player. Very few injuries to this region of the body were the result

\author{
- lower limb 51\% \\ upper limb $14 \%$ \\ Torso/back $1 \%$ \\ - head/face $34 \%$
}

of contact with the ground (4\%). This pattern varied depending on the type of head/face injury. Most of the concussions (47\%) were caused by collisions with another player, whereas a stick caused most of the wounds (68\%). Finally, a ball caused $60 \%$ of the black eyes. 
Figure (3)

Cause of reported head or face injuries to female field hockey players that occurred during a field hockey game or practice

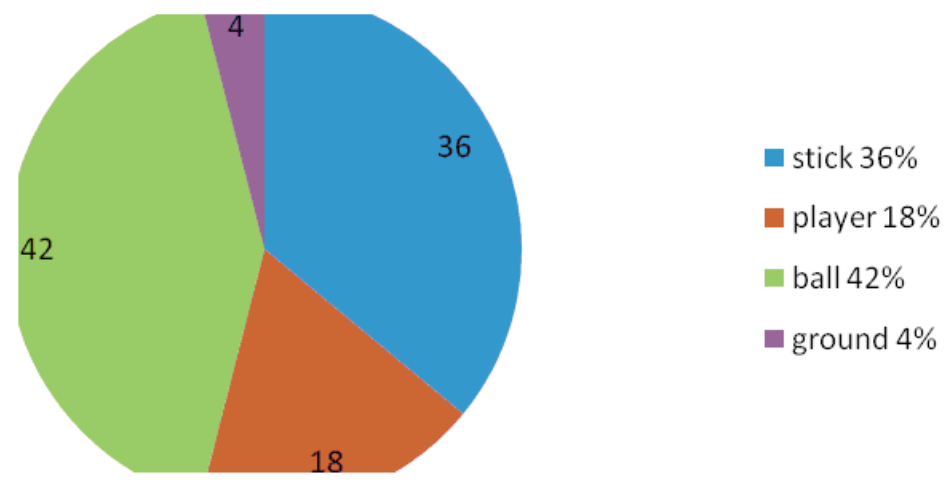

Dividing the sample according to the position played resulted in the formation of the following five groups: goalkeepers $(\mathrm{N}=11)$, backfield players $(\mathrm{N}=44)$, midfielders $(\mathrm{N}=27)$, and forwards $(\mathrm{N}=46)$. Those who reported that they played more than one position were placed in a separate group (multiple, $\mathrm{N}=30$ ). Table 1 lists some characteristics of these groups including

Table (2)

The number of specific traumatic injuries sustained by female field hockey players (N represents the number of players surveyed at each position)

\begin{tabular}{|c|c|c|c|c|c|c|}
\hline & Goal $n=11$ & $\begin{array}{c}\text { Backfield } \\
n=44\end{array}$ & $\begin{array}{c}\text { Midfield } \\
n=27\end{array}$ & $\begin{array}{c}\text { Forward } \\
n=46\end{array}$ & $\begin{array}{c}\text { Multiple } \\
n=30\end{array}$ & Total $n=158$ \\
\hline \multicolumn{7}{|c|}{ Head / face } \\
\hline Bruise & 4 & 11 & 16 & 21 & 18 & 70 \\
\hline Wound & 1 & 3 & 16 & 9 & 11 & 40 \\
\hline Concussion & 12 & 5 & 2 & 10 & 7 & 36 \\
\hline Broken nose & 1 & 2 & 3 & 4 & 4 & 14 \\
\hline Dislocation & 0 & 0 & 1 & 0 & 0 & 1 \\
\hline Total & 18 & 21 & 38 & 44 & 40 & 161 \\
\hline \multicolumn{7}{|c|}{ Upper limb } \\
\hline Fracture & 9 & 7 & 10 & 8 & 11 & 45 \\
\hline Sprain & 1 & 3 & 2 & 2 & 1 & 9 \\
\hline Dislocation & 0 & 0 & 2 & 2 & 1 & 5 \\
\hline Bruise & 1 & 1 & 0 & 1 & 0 & 3 \\
\hline Wound & 0 & 0 & 1 & 0 & 1 & 2 \\
\hline Total & 11 & 11 & 15 & 13 & 14 & 64 \\
\hline \multicolumn{7}{|c|}{ Torso } \\
\hline Fracture & 3 & 0 & 0 & 0 & 0 & 3 \\
\hline Strain & 0 & 1 & 0 & 0 & 1 & 2 \\
\hline Total & 3 & 1 & 0 & $\mathbf{0}$ & 1 & 5 \\
\hline \multicolumn{7}{|c|}{ Lower limb } \\
\hline Ankle sprain & 6 & 57 & 21 & 31 & 43 & 158 \\
\hline $\begin{array}{c}\text { Muscle } \\
\text { strain }\end{array}$ & 6 & 3 & 7 & 13 & 9 & 38 \\
\hline Knee injury & 5 & 6 & 4 & 1 & 3 & 19 \\
\hline Fracture & 2 & 5 & 2 & 4 & 2 & 15 \\
\hline Bruise & 1 & 1 & 1 & 2 & 2 & 7 \\
\hline Wound & 0 & 1 & 0 & 0 & 1 & 2 \\
\hline Total & 20 & 73 & 35 & 51 & 60 & 239 \\
\hline
\end{tabular}


The overall rate of injury was 0.44 injuries per athlete-year. This rate included 0.22 injuries/athlete/year to the lower limb, 0.15 to the head face, 0.06 to the upper limb, and 0.005 injuries/athlete-year to the back or torso. Overall, goalkeepers had the highest risk of injury (0.58 injuries/athlete/year), including the highest rate of upper limb (0.12 injuries/athleteyear) and back/torso injury $(0.03$ injuries/athlete-year). In fact, they had a rate of back and torso injury 16.7 times higher than the rate calculated for field players. The most common injuries to goalkeepers were (in order of the number of occurrences reported): concussions, wrist fractures, ankle sprains, thigh muscle strains, and knee ligament tears. The majority of these injuries occurred due to contact with other players, the playing surface, or the goal itself. Those who played multiple positions had the highest total injury rate of the field players (0.51 injuries/athlete/year). This group also had the highest rate of lower limb injury with 0.27 injuries/athlete/year. The most common injuries were ankle sprains, contusions to the head/face region, and finger fractures.

Table (2) also shows that midfielders had the highest injury rate of the field players who played only one position on a regular basis $(0.36$ injuries/athlete/year). The midfielders also presented the highest rate of injuries to the head/face region (0.21 injuries/athlete/year) and the most injuries to the upper limb of all field players. The most common injuries to this group (ankle sprains, wounds, or contusions to the head/face and finger fractures) were the same as those reported by athletes who played multiple positions. Forwards and backfield players had similar rates of injury $(0.37$ and 0.36 injuries/athlete/year, respectively). The top two injuries for these groups (ankle sprains and black eyes) were also the same.

However, there were also notable differences between the two positions. For instance, backfield players had a higher rate of lower limb injury (0.25 vs 0.18 injuries/athlete-year). The next two most common injuries to backfield players were finger fractures and knee ligament tears, whereas forwards had more concussions and lower limb muscle strains. Finally, when compared with backfield players, forwards had a higher rate of injury to the head and face by a factor of 2.1. Even though back pain is not necessarily related to acute injury, it appeared to be a common complaint among the players. Therefore, they were also asked some standard questions relating to back injury and pain (Table 3). Although 59\% indicated that they had experienced pain at some time, only 50\% reported that back pain affected them during the field hockey season. The pain was serious enough to cause $12 \%$ of athletes to miss a field hockey game or time at school or work. The lower back was the most common site of pain followed by the upper back, neck, tailbone, and ribs.

Table (3)

Reports of back pain in female field hockey players

\begin{tabular}{|l|c|}
\hline \multicolumn{2}{|c|}{ Experience of pain } \\
\hline \multicolumn{2}{|c|}{ Players reporting } \\
\hline Any time & $59 \%$ \\
\hline During season & $50 \%$ \\
\hline Injury & $31 \%$ \\
\hline \multicolumn{2}{|c|}{} \\
\hline Affects performance of pain \\
\hline Missed games & $24 \%$ \\
\hline Missed practice & $8 \%$ \\
\hline Missed school or work & $15 \%$ \\
\hline \multicolumn{2}{|c|}{ Site of pain } \\
\hline Neck & $7 \%$ \\
\hline Upper back & $15 \%$ \\
\hline Ribs & $19 \%$ \\
\hline Lower back & $6 \%$ \\
\hline Tail bone & $54 \%$ \\
\hline
\end{tabular}


Table (2) also shows that the goal keepers had the least percentage of traumatic injuries with $7.12 \%$ while forward players had the highest percentage rate with $24.05 \%$ which means that defenders are exposed to traumatic injuries due to their continuous engagement with opponent's backward players.

\section{Discussion:}

The general pattern of field hockey injuries presented in this study supports the findings of other authors. The most frequent site of injury was the lower limb, followed by the head and face, upper limb, and finally the torso $(8,18,19$, and 21). An ankle sprain was the most common single injury. This result is not unique to field hockey as the lateral ankle is the most frequently injured area in the body, and, overall, an ankle sprain is the most common injury in sport $(7,25)$. Whether the mechanism of injury in field hockey is the same as in other field sports, such as soccer, has yet to be determined.

Fox (6) suggests that the stooped position used when dribbling the ball may be an unsound position for fast locomotion and could contribute to lower limb injury. It is interesting to note that studies conducted before 1980 have reported lower incidences of upper limb injuries than more recent reports. Graham and Bruce (8) surveyed intercollegiate athletic injuries during the 1974-75 school year in Virginia and found $10.6 \%$ of total injuries to the upper limb, and Rose (21) reported $4.9 \%$ at the California State University in Long Beach from 1976 to 1979. Recent surveys of collegiate and high school field hockey (including the current study) indicate that $14.0 \%$ to $15.8 \%$ of the total injuries are to the upper limb and most of these are wrist or finger fractures $(18,19)$. It is possible that this difference is due to changes in the game that have occurred over the past two decades. For example, improved stick construction allows players to hit the ball with greater velocity and different techniques for stopping the ball on artificial turf may have led to an increased risk of upper limb injury.

The second most frequent site of injury in field hockey is the head and face region (Table 2). The percentage of athletes who had sustained at least one injury to this area was $42 \%$, and the uninjured players tended to be younger and have less experience than injured players. Because only active players were surveyed, these findings do not include those who may have stopped playing due to serious or catastrophic injury. It appears that if an athlete play long enough, they are likely to experience a head or face injury. This statement is supported by a survey conducted on international athletes (1). It was found that $62 \%$ of these elite level athletes had a facial injury at least once, and the high value was attributed to their increased exposure time and tendency to take more risks.

Although no catastrophic injuries were reported in this study, the high rate of injury to the head and face region indicates that the potential for such injury still exists. Elliott and Jones (4) reported three penetrating eye injuries to female field hockey players in one season. All of these injuries were caused by a stick, as were $36 \%$ of the head and face injuries in this study. Findings such as these have led to the suggestion that a helmet with a full visor be required in field hockey. Yet, this study found that goalkeepers, who are already wearing helmets, had the highest rate of concussions. If protective equipment is deemed necessary, the impact of equipment changes on potential injuries, as well as the character and nature of the game, must be carefully considered $(10,11)$.

With the above concerns in mind, a more immediate approach to reducing severe injury would include education about the risks of head and eye injury and strict enforcement of the current rules. For example, a recent survey indicated that parents saw a need for the mandatory use of mouth-guards in field hockey (3). Mouth protectors have been shown to decrease concussions, cerebral hemorrhages, unconsciousness, jaw fractures, and lacerations of the lips and cheeks $(9,16)$. Despite these benefits and widespread regulations enforcing the use of mouth-guards, many players still do not wear them (1). The most common reason that was cited for not wearing the protector was discomfort. Also, most of the players who wore the mouth-guard did so because they had already sustained an injury.

Modified rules and a progressive introduction to field hockey for children could reduce injuries in these players. Umpires and coaches should 
also be continuously trained so that there is consistent skill development and interpretation of rules to minimize unsafe play (22). The finding that goalkeepers had the highest injury rate per athlete-year supports suggestions that goalkeepers are at the highest risk of injury in field hockey $(6,17,23)$. However, most injuries did not occur due to contact with the ball, as proposed, but due to contact with another player, the ground, or the goal itself. It has also been implied that the most injured field players would be forwards or defenders, who spend more time near the goal area (6). So, it was surprising to find that midfielders actually had the highest rate of injury, including the highest rate of injury to the head/face region and to the upper limb. It is possible that these injuries were due to greater fatigue or the type of defense that midfielders tend play during the game. Four positions were tested during match play using a heart rate monitor (2). It was found that the center half and inside forwards spent more time at a higher physical intensity than other positions (these positions are closest to the definition of midfielders used in this study). An increased level of physical intensity could lead to errors in play and possibly injury. Midfielders also execute most defensive skills in a recovery mode. When making a chase tackle from the rear of a player about to strike a ball, great care is needed to avoid the backward swing of the stick. Otherwise, severe stick-inflicted injuries could occur. These include injuries to the nose, face, and teeth (6). In fact, up to $20 \%$ of field hockey injuries have been attributed to "tackling" (8).

One might expect to find similar rates of injury among forwards and backs as was reported in this study. Players in both positions tend to spend most of their time in the same area of the field. One attempts to score a goal and the other defends. Some coaches and players have suggested that the elimination of the offside rule has not necessarily increased the pace of the game or goal scoring. Instead, many teams have adopted a strategy of filling the striking circle with as many defenders as possible. This tactic may increase the risk of injury to forwards and defenders as more players crowd the goal area. To determine why different types of injuries occur to each player, further investigation into the mechanism of injury and the playing situation in which these injuries occur is required. Back pain continues to be a common complaint of field hockey players. It was found that $59 \%$ of athletes have experienced back pain and the most common site of pain is the lower back. These results are similar to previous reports (20).

Some authors have attempted to attribute low back pain to stresses on the spine unique to field hockey. For example, it has been shown that 7 min of dribbling a field hockey ball can cause an average spinal shrinkage of $2.73 \mathrm{~mm}$ (20). Yet, no obvious relationship between lumbar mobility and low back pain in field hockey players has been demonstrated (15). However, players without pain may be stronger in peak eccentric extension strength than players who experience pain (5). It may seem as if 59\% of athletes reporting back pain is a high proportion in such a young and active group. However, other sources have indicated that back pain is very prevalent in the general population (60$80 \%)$ and among athletes (50-85\%) (13,24). Furthermore, by the age of 18 , over $50 \%$ of girls have experienced at least one episode of low back pain (14). Thus, the possibility emerges that the pain reported by field hockey players cannot be directly attributed to the sport, but further research would be required to support or refute such a suggestion.

\section{Conclusions:}

This study demonstrated that the most prevalent injuries in field hockey are ankle sprains, hand fractures, and head or face injuries. It also revealed that, not only is there a difference in the rate of injury between playing positions, but also in the types of injuries sustained at different positions. Most of these injuries are not severe. In fact, field hockey tends to have low serious injury rates when compared with other sports. In the NCAA, field hockey was fourth among the women's sports covered, behind gymnastics, soccer, and basketball (18). Of five popular high-school sports played by girls (including basketball, field hockey, soccer, softball, and volleyball), field hockey had the lowest number of injuries requiring surgery or more than $7 \mathrm{~d}$ of time lost (19). 
Yet, the nature of severe injuries in field hockey and the high rate of head/face injury indicate a serious risk. Now that these patterns have been identified, further examination of the playing situations that lead to injury should be undertaken. It seems that reducing these types of injuries will require a multifaceted approach. This approach must include the education of players, coaches, and officials along with considering the development of rule changes and sport-specific protective equipment.

Also further studies are needed to improve data collection at the club and association level to gain a more accurate picture of the incidence, pattern and severity of all hockey injuries. The use of consistent definitions of injury and standardized classification systems should be promoted. There is a need to include measures of exposure in hockey research (for example, injuries per 100 hours of match play and practice) so that findings from studies are more easily compared.

\section{References:}

1. BOLHUIS, J. H. A., J. M. M. LEURS, and G. E. FLOGEL. Dental and facial injuries in international field hockey. Br. J. Sports Med. 21:174-177, 1987.

2. CIBICH, B. Application of sport science to hockey. Sports Coach, April-June: 3-6, 1991.

3. DIAB N., and A. P. MOURINO. Parental attitudes toward mouth-guards. Pediatr. Dentistry 19:455-460, 1997.

4. ELLIOT, A. J., and D. JONES. Major ocular trauma: a disturbing trend in field hockey injuries. Br. Med. J. (Clin. Res. Ed.) 289: 21$22,1984$.

5. FENETY, A., and S. KUMAR. Iso-kinetic trunk strength and lumbo-sacral range of motion in elite female field hockey players reporting low back pain. J. Orthop. Sports Phys. Therapy 16:129-135, 1992.

6. FOX, N. Risks in field hockey. In: Sports Fitness and Sports Injuries, T. Reilly (Ed.) Boston: Faber \& Faber, 1981, pp. 112- 117.

7. GARRICK, J. G. The frequency of injury, mechanism of injury, and epidemiology of ankle sprains. Am. J. Sports Med. 5:241-242, 1977.
8. GRAHAM, G. P., and P. J. BRUCE. Survey of intercollegiate athletic injuries to women. Res. Q. 48:217-220, 1977.

9. JOHNSEN, D. C., and J. E. WINTERS. Prevention of intraoral trauma in sports. Dental Clin. North Am. 35:657-666, 1991.

10. JONES, N. P. Eye injury in sport: incidence, biomechanics, clinical effects and prevention. J. R. Coll. Surg. Edinburgh 38:127-133, 1993.

11. JONES, N. P. Eye injury in sport. Sports Med. 7:163-181, 1989.

12. JONES, N. P. One year of severe eye injuries in sport. Eye 2:484-487, 1988.

13. KELSEY, J. L., and M. C. HOCHBERG. Epidemiology of chronic musculoskeletal disorders. Ann. Rev. Public Health 9:379-401, 1988.

14. LEBOEF-YDE, C., and K. O. KYVIK. At what age does low back pain become a common problem? Spine. 23:228 -234, 1998.

15. LINDGREN, S., and L. TWOMEY. Spinal mobility and trunk muscle strength in elite hockey players. The Australian J. of Physiotherapy 34(3):123-130, 1988.

16. MCNUTT, T., S. W. SHANNON Jr., J. T. WRIGHT, and R. A. FEINSTEIN. Oral trauma in adolescent athletes: a study of mouth protectors. Pediatr. Dentistry 11:209 -213, 1989.

17. MOORE, S. Field hockey. In: Catastrophic Injuries in Sports: Avoidance Strategies, 2nd Ed., S. H. Adams, M. J. Adrian, and M. A. Bayless (Eds.). Indianapolis, IN: Benchmark Press Inc., 1987, pp. 67-74.

18. NATIONAL COLLEGIATE ATHLETIC ASSOCIATION. N.C.A.A. Injury Surveillance System Reports: 1998-99 Field hockey. Overland Park, KS, 1999.

19. POWELL, J. W., and K. D. BARBERFOSS. Injury patterns in selected high school sports: a review of the 1995-1997 seasons. J. Athl. Training 34:277-284, 1999.

20. REILLY, T., and A. SEATON. Physiological strain unique to field hockey. J. Sportsmed. Phys. Fitness 30:142-146, 1990. 
21. ROSE, C. P. Injuries in women's field hockey: a four-year study. Physician Sportsmed. 9(3):97-98, 100, 1981.

22. SHERKER S., and E. CASSELL. Report No. 143: a Review of Field Hockey Injuries and Countermeasures for Prevention. Clayton, Victoria, AU: Monash University Accident Research Centre, 1998.

23. SPEDDING, I. Is there a risk of injury in modern hockey? Sports Coach 10(1):3- 4, 1986.
24. SWARD, L., M. HELLSTROM, B. JACOBSSON, and L. PETERSON. Back pain and radiologic changes in the thoraco-lumbar spine of athletes. Am. J. of Sports Med. 16:530 $-533,1988$.

25. TORG, J. Ankle and foot problems in the athlete. Clin. Sports Med. 1:77-84, 1982.

26. WAlTER, S. D., J. R. SUTTON, J. M. MCINTOSH, and C. CONNOLY. The aetiology of sport injuries: a review of methodologies. Sports Med. 2:47-58, 1985. 